\title{
Assisted reproductive technology and the risk of gestational diabetes mellitus: a systematic review and meta-analysis
}

\author{
Maryam Mohammadi ${ }^{1,2}$, Esmaeil Khedmati Morasae ${ }^{3}$, Saman Maroufizadeh ${ }^{4 *}$ (D) Amir Almasi-Hashiani ${ }^{5}$, \\ Behnaz Navid ${ }^{1}$, Payam Amini ${ }^{6}$, Reza Omani-Samani ${ }^{7}$ and Ahad Alizadeh ${ }^{8^{*}}$
}

\begin{abstract}
Background: The use of assisted reproductive technology (ART) is increasing worldwide, and observational studies have indicated that women who conceived by ART have an increased risk of pregnancy complications including gestational diabetes mellitus (GDM). We aimed to determine the risk of GDM among women who conceived with ART by systematic review and meta-analysis.

Main text: A systematic literature search was conducted in ISI Web of Knowledge, MEDLINE, Scopus, and Embase through May 2017 for English-language articles using a list of keywords. All studies comparing GDM in women conceived by ART and those who conceived spontaneously were included. Data extraction was performed by two authors independently and discrepancies were resolved by discussion. In total, 48 studies with 91,487 pregnancies conceived through ART and 2,525,234 spontaneously conceived met the inclusion criteria. There was evidence of substantial heterogeneity among these studies $\left(P<0.001, P^{2}=98.6 \%\right)$. Random effects meta-analysis showed a significant increase in GDM among those who conceived by ART compared with those who conceived spontaneously (pooled relative risk $=1.51,95 \%$ confidence interval $=1.18-1.93$ ). Visual inspection of the funnel plot did not reveal any publication bias, which was supported by Egger's test and Begg's test.

Conclusion: The findings of this systematic review indicate that the use of ART treatment is associated with a 1.51fold increase in GDM. Women need to be counselled carefully before undergoing ART treatment about the possibility and risk of GDM.
\end{abstract}

Keywords: Assisted reproductive technology, Gestational diabetes mellitus, Infertility, Meta-analysis, Systematic review

\section{Background}

Assisted reproductive technology (ART) is a group of medical methods for treating the infertile human in which both male and female gametes are used outside the body to achieve pregnancy [1]. To date, approximately 5 million babies are born worldwide via ART [2]. Although ART may help infertile couples, its use has increased concerns associated with pregnancy-related complications and adverse consequences [3]. It has been suggested that obstetric outcomes in gestation after ART are poor when

\footnotetext{
*Correspondence: saman.maroufizadeh@gmail.com; st.alizadeh@gmail.com ${ }^{4}$ School of Nursing and Midwifery, Guilan University of Medical Sciences, Rasht, Iran

${ }^{8}$ Metabolic Diseases Research Center, Qazvin University of Medical Sciences, Qazvin, Iran

Full list of author information is available at the end of the article
}

compared with those pregnancies spontaneously conceived [4]. Moreover, evidence from meta-analyses [4-8] has revealed that singleton pregnancies after ART are at higher risk of adverse consequences than those conceived naturally. One of the outcomes followed by ART is gestational diabetes mellitus (GDM) and is known as one of the most common complications in pregnancy $[9,10]$. GDM is defined as "carbohydrate intolerance of variable severity with onset or first recognition during pregnancy" [11]. GDM is a worldwide public health problem and complicates about $7 \%$ of all pregnancies [12, 13]. The cause and pathogenesis of GDM is both multifunctional and complex [14]. GDM is prone to causing a woman and her baby a wide range of complications during pregnancy and in later life $[15,16]$. women with GDM are more 
likely to develop metabolic syndrome in the future, including type 2 diabetes [17]. Therefore, it is important to realize the risk factors of GDM such as family history of diabetes, obesity, high parity, advanced maternal age, previous adverse pregnancy, non-white race, history of a baby with birth weight $>3800 \mathrm{~g}$, and hypothyroidism $[12,18]$.

In addition, studies have indicated that ART pregnancies are related to an increased risk of GDM [19-22]. Another study in Australia reported those who underwent ART are more prone to experience GDM compared to those who conceived spontaneously [23]. However, it was shown in another study that the rate of GDM was lower in women who conceived under intracytoplasmic sperm injection (ICSI) compared to those of spontaneously, in vitro fertilization (IVF) or simple ART [24]. Finally, we conducted a meta-analysis to provide an up-to-date survey of pregnancies resulting from ART and the increased risk of GDM between 1997 and 2017. We aimed to investigate the higher risk of GDM in pregnancies following ART and compare them to those of spontaneous conceptions.

\section{Material and methods}

\section{Search strategy}

This systematic review adheres to the PRISMA (Preferred Reporting Items for Systematic Reviews and Meta-Analyses) checklist [25]. We searched the electronic databases ISI Web of Knowledge, MEDLINE/ PubMed, Scopus, and Embase through May 2017, for studies investigating the relationship between ART and GDM. The search terms used were presented in Table 1. Reference lists from all identified studies were also searched for any relevant articles. Two authors (MM and AA) evaluated the studies, and discrepancies were resolved by discussion.

\section{Inclusion and exclusion criteria}

We included published studies that examined the relationship between the use of ART and the risk of GDM. No restriction criteria were imposed with regard to the size or type of the studied population, nor to the type of ART treatment. The following study types were excluded from the analyses: (a) non-English articles; (b) animal studies; (c) repeated or overlapping studies; (d) reviews, meta-analyses, case reports, editorials, and letters-to-the-editor articles; and (e) unpublished studies.

\section{Outcome and exposure}

The exposure variable was all types of ART treatment. Our outcome was GDM, defined as "carbohydrate intolerance of variable severity with onset or first recognition during pregnancy" [11].
Table 1 Search strategy for MEDLINE (MeSH, Medical Subject Headings)

\begin{tabular}{ll}
\hline & Word or term \\
\hline 1 & Gestational Diabetes Mellitus [Text word]) \\
3 & "Gestational Diabetes Mellitus" [Text word]) \\
4 & Diabetes, Gestational [Text Word]) \\
5 & "Diabetes, Gestational" [Text Word]) \\
6 & "Diabetes, Gestational" [Mesh] \\
7 & 1 OR 2 OR 3 OR 4 OR 5 \\
8 & Reproductive techniques, assisted [Text word] \\
9 & Reproductive techniques, assisted [MeSH terms] \\
10 & 7 OR 8 \\
11 & Cohort studies [Text word] \\
12 & Cohort studies [MeSH terms] \\
13 & Retrospective studies [Text word] \\
14 & Retrospective studies [MeSH terms] \\
15 & Prospective studies [Text word] \\
16 & Prospective studies [MeSH terms] \\
17 & Case-control studies [Text word] \\
18 & Case-control studies [MeSH terms] \\
19 & 10 OR 11 OR 12 OR 13 OR 14 OR 15 OR 16 OR 17 \\
\hline
\end{tabular}

\section{Data extraction and quality assessment}

Two reviewers (MM and AA) independently abstracted the following data from all eligible articles: first author's name; year of publication; location; study period; design; sample size; type of ART; and study findings. Discrepancies were resolved by discussion between two reviewers.

Quality assessment of included studies was performed independently by two reviewers using the NewcastleOttawa Scale (NOS) [26]. The NOS assesses the methodological quality of the observational studies according to three domains: (a) selection of study groups; (b) comparability of groups; and (c) ascertainment of exposure and outcomes. Total scores range from 0 (lowest quality) to 9 (highest quality).

\section{Statistical analysis}

Data were analyzed using STATA version 13.0 (Stata Corp, College Station, TX, USA). The pooled relative risk (RR) was calculated with its 95\% confidence interval (CI) to assess the strength of the association between the use of ART and GDM risk. To assess between study heterogeneity, both the Cochran $Q$ test and the $I^{2}$ statistic (the percentage of total variation across studies attributable to heterogeneity beyond chance) were calculated [27]. $I^{2}$ values of 25,50 , and $75 \%$ were used as evidence of low, moderate, and high heterogeneity, respectively [27]. Subgroup analysis was performed to detect factors 
that may explain heterogeneity in outcome between each study. Publication bias was assessed using visual inspection of a funnel plot, Egger's test, and Begg's test [28, 29]. In all statistical tests, results with $P<0.05$ were deemed statistically significant, except for the Cochran $Q$ test where $P<0.10$ was used.

\section{Results}

\section{Study selection}

The steps of the study selection are displayed in Fig. 1 . A total of 950 related published articles were retrieved by using a search strategy in four international databases (638 from Scopus, 91 from PubMed, 62 from ISI Web of Knowledge, and 159 from Embase) and also seven records were identified from Google Scholar and reference lists of final included papers in the meta-analysis. In this study, 829 papers remained after removing duplicate papers using EndNote software. After title and abstract screening, 278 relevant articles were recognized as eligible and they were considered for additional full-text screening. After excluding 230 non-eligible studies, finally, 48 studies (four case-control studies, three cross- sectional studies, and 41 cohort studies) were included in this meta-analysis.

\section{Study characteristics}

The study characteristics of the included studies are summarized in Table 2. In total, we included 48 studies published from 1987 to 2017. Observational studies (i.e., cross-sectional, case control and cohort studies) were included in the meta-analysis, whereas non-English studies and studies without relevant data or partial data were excluded. Sample size in the ART group ranged from 31 to 21,615 cases and in the non-ART group it ranged from 20 to 595,168 cases. Of the 48 studies, 19 were conducted in Asia, 17 in Europe, and 12 in America. Fourteen studies were published before 2011 and 34 studies were published from 2011 to 2017.

\section{Quantitative data synthesis}

In the present study, 91,487 ART cases (with 6819 cases of GDM) and 2,525,234 non-ART cases (with 113,505 cases of GDM) were included in the analysis. RRs and their 95\% CIs were calculated using the Mantel-Haenszel method and, because of significant heterogeneity

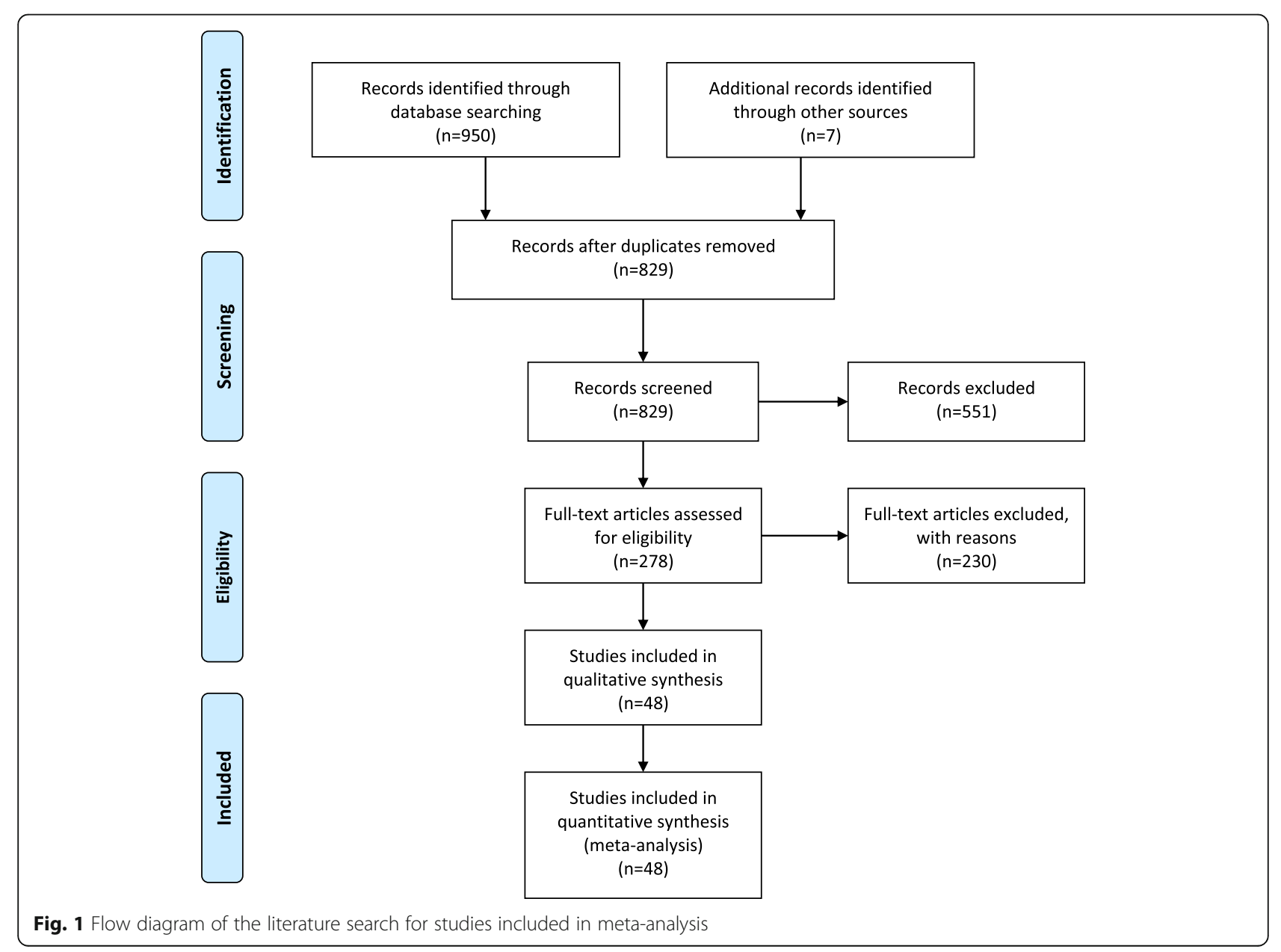


Table 2 Characteristics of the primary studies included in the meta-analysis

\begin{tabular}{|c|c|c|c|c|c|c|c|c|c|c|c|}
\hline \multirow[t]{2}{*}{ First author } & \multirow[t]{2}{*}{ DOP } & \multirow[t]{2}{*}{ Country } & \multirow[t]{2}{*}{ Period } & \multirow[t]{2}{*}{ Design } & \multicolumn{2}{|c|}{ Mean of age } & \multirow[t]{2}{*}{$\begin{array}{l}\text { Type of } \\
\text { ART }\end{array}$} & \multicolumn{2}{|c|}{$\begin{array}{l}\text { \# of GDM in } \\
\text { ART group }\end{array}$} & \multicolumn{2}{|c|}{$\begin{array}{l}\text { \# of GDM in } \\
\text { non-ART group }\end{array}$} \\
\hline & & & & & ART & Non-ART & & $n(\mathrm{GDM})$ & $N$ (Total) & $n(\mathrm{GDM})$ & $N$ (Total) \\
\hline Varma TR [30] & 1987 & UK & 1983-1985 & Cohort & NA & NA & NA & 7 & 362 & 67 & 7284 \\
\hline Vollenhoven B [31] & 2000 & Australia & 1990-1997 & Case-Control & NA & NA & $\mathrm{Ol}$ & 22 & 60 & 10 & 60 \\
\hline Bjercke S [32] & 2002 & Norway & 1993-1998 & Cohort & 31.32 & 32.7 & IVF & 4 & 52 & 2 & 355 \\
\hline Koivurova S [33] & 2002 & Finland & 1990-1995 & Cohort & 31.8 & 31.8 & IVF & 12 & 225 & 21 & 671 \\
\hline Nassar AH [34] & 2003 & USA & 1995-2000 & Cohort & 35 & 36 & IVF & 3 & 56 & 6 & 112 \\
\hline Pinborg A [35] & 2004 & Denmark & 1997 & Cohort & 33.1 & 30.5 & IVF/ICSI & 13 & 236 & 16 & 566 \\
\hline Shevell T [36] & 2005 & USA & 1999-2002 & Cohort & 33.19 & 29.9 & IVF/OI & 92 & 1776 & 1166 & 34,286 \\
\hline Saygan-Karamürsel B [21] & 2006 & Turkey & 1999-2003 & Case-Control & 31.45 & 28.94 & $|\mathrm{CS}|$ & 22 & 274 & 10 & 348 \\
\hline Buckett WM [37] & 2007 & Canada & 1998-2003 & Cohort & 34.375 & 34 & IVF/ICSI/IVM & 39 & 344 & 25 & 344 \\
\hline Adler-Levy Y [22] & 2007 & Israel & 1988-2002 & Case-Control & 30.27 & 29.4 & IVF/OI & 96 & 1036 & 153 & 3694 \\
\hline Eskandar M [38] & 2007 & Saudi Arabia & 2004-2006 & Cohort & 28.29 & 26.44 & $|\mathrm{CS}|$ & 3 & 35 & 7 & 73 \\
\hline Krieg SA [39] & 2008 & USA & $2001-2005$ & Cohort & 42.7 & 41.3 & IVF & 10 & 71 & 9 & 108 \\
\hline Vasario E [40] & 2010 & Italy & 2004-2008 & Cohort & 31.5 & 33.5 & IVF & 10 & 84 & 13 & 139 \\
\hline Suzuki S [41] & 2010 & Japan & 2000-2007 & Cohort & 37.8 & 37.9 & IVF & 1 & 64 & 1 & 87 \\
\hline Tepper NK [42] & 2011 & USA & 1997-2004 & Cohort & 36 & 30 & NA & 112 & 6256 & 4434 & 595,168 \\
\hline Montoya JB [43] & 2012 & Mexico & 2005-2009 & Cohort & 32.5 & 31.6 & NA & 7 & 57 & 7 & 57 \\
\hline Moini A [44] & 2012 & Iran & 2008-2010 & Cohort & 30.6 & 27.3 & IVF/ICSI & 21 & 230 & 15 & 170 \\
\hline Bamberg C [45] & 2012 & Germany & 1998-2008 & Cohort & 32.5 & 30.1 & IVF/ICSI & 19 & 426 & 26 & 813 \\
\hline Le Ray C [46] & 2012 & France & 2008-2010 & Cohort & $>43$ & $>43$ & IVF/OD & 11 & 144 & 12 & 236 \\
\hline Werder E [47] & 2013 & USA & $2002-2008$ & Cohort & NA & NA & IVF & 155 & 2233 & 30 & 299 \\
\hline Wang Y [48] & 2013 & Australia & 2007-2009 & Cross-Sectional & NA & NA & NA & 1044 & 13,732 & 19,333 & 386,660 \\
\hline Farhi A [49] & 2013 & Israel & 2006-2008 & Cohort & & & IVF/ICSI & 61 & 561 & 59 & 600 \\
\hline Toshimitsu M [50] & 2014 & Japan & 2006-2010 & Cohort & NA & NA & IVF/ICSI & 0 & 116 & 6 & 664 \\
\hline Castera D [51] & 2014 & Italy & 2007-2011 & Cohort & 38.5 & 33.5 & IVF/ICSI & 14 & 138 & 6 & 207 \\
\hline Ashrafi M [52] & 2014 & Iran & $2011-2012$ & Cross-Sectional & 30 & 26.4 & IVF & 174 & 468 & 17 & 234 \\
\hline Ashrafi M [53] & 2014 & Iran & $2011-2012$ & Cross-Sectional & 30.35 & 26.6 & ICSI/IVF/IU| & 13 & 54 & 4 & 20 \\
\hline Silberstein T [54] & 2014 & Israel & 1988-2006 & Cohort & 30.9 & 28.49 & IVF/OI & 492 & 3268 & 11,319 & 171,513 \\
\hline Yang X [55] & 2014 & China & 2011 & Cohort & NA & NA & ART & 172 & 1139 & 5179 & 111,264 \\
\hline Domingues A [56] & 2014 & Portugal & 1996-2011 & Cohort & NA & NA & IVF/ICSI & 15 & 180 & 31 & 698 \\
\hline Stern JE [57] & 2015 & USA & 2004-2008 & Cohort & NA & NA & NA & 81 & 3689 & 3363 & 302,085 \\
\hline Jie Z [58] & 2015 & China & 2010-2013 & Cohort & 32.53 & 29.87 & & 48 & 428 & 190 & 2788 \\
\hline Nunes F [59] & 2015 & NA & NA & Case-Control & 34.3 & 31.4 & NA & 11 & 77 & 23 & 208 \\
\hline Barua S [60] & 2016 & Australia & 2007-2010 & Cohort & 32.1 & 29.2 & ART & 224 & 1727 & 3270 & 48,654 \\
\hline Zhu L [61] & 2016 & China & 2006-2014 & Cohort & 31.84 & 31.73 & IVF/ICSI & 309 & 2641 & 342 & 5282 \\
\hline Martin AS [62] & 2016 & USA & 2008-2012 & Cohort & NA & NA & ART & 397 & 14,761 & 22,925 & 100,857 \\
\hline Luke B [63] & 2016 & USA & 2004-2010 & Cohort & 36.65 & 30.1 & ART & 93 & 1338 & 2951 & 56,755 \\
\hline Bashmakova NV [64] & 2016 & Russia & NA & Cohort & NA & NA & ART & 12 & 37 & 6 & 96 \\
\hline Rosato E [65] & 2016 & Italy & 2010-2011 & Cohort & 44.2 & 44.1 & ART & 6 & 72 & 6 & 80 \\
\hline Valenzuela-Icaraz B [66] & 2016 & Spain & 2004-2010 & Cohort & 33.46 & 31 & IVF/ICSI/OI & 17 & 488 & 4 & 200 \\
\hline Marton V [67] & 2016 & Sweden & 1994-2014 & Cohort & 35.25 & 33.275 & IVF/ICSI & 54 & 312 & 44 & 912 \\
\hline Beyer DA [68] & 2016 & German & NA & Cohort & 39 & 39 & IVF/ICSI & 4 & 467 & 161 & 6417 \\
\hline Pourali L [69] & 2016 & Iran & 2009-2014 & Cohort & 28.9 & 27.1 & ART & 8 & 31 & 8 & 96 \\
\hline
\end{tabular}


Table 2 Characteristics of the primary studies included in the meta-analysis (Continued)

\begin{tabular}{|c|c|c|c|c|c|c|c|c|c|c|c|}
\hline \multirow[t]{2}{*}{ First author } & \multirow[t]{2}{*}{ DOP } & \multirow[t]{2}{*}{ Country } & \multirow[t]{2}{*}{ Period } & \multirow[t]{2}{*}{ Design } & \multicolumn{2}{|c|}{ Mean of age } & \multirow[t]{2}{*}{$\begin{array}{l}\text { Type of } \\
\text { ART }\end{array}$} & \multicolumn{2}{|c|}{$\begin{array}{l}\text { \# of GDM in } \\
\text { ART group }\end{array}$} & \multicolumn{2}{|c|}{$\begin{array}{l}\text { \# of GDM in } \\
\text { non-ART group }\end{array}$} \\
\hline & & & & & ART & Non-ART & & $n$ (GDM) & $N$ (Total) & $n(\mathrm{GDM})$ & $N$ (Total) \\
\hline Ben-Yaakov RD [70] & 2016 & Israel & 1988-2012 & Cohort & 30.9 & 28.7 & IVF/OI & 585 & 4153 & 5895 & 95,138 \\
\hline Qin J [71] & 2016 & China & 2013-2016 & Cohort & 31.3 & 29.26 & IVF & 165 & 1260 & 823 & 4379 \\
\hline Wang YPA [72] & 2016 & Australia & $2007-2011$ & Cohort & NA & NA & NA & 1736 & 21,615 & 30,869 & 574,905 \\
\hline Korosec S [73] & 2016 & Slovenia & 2004-2011 & Cohort & 33.42 & 33.42 & IVF/ET/FET & 43 & 1127 & 129 & 3381 \\
\hline Morency AM [74] & 2016 & Canada & 2000-2013 & Cohort & 33 & 31.4 & ART & 4 & 49 & 19 & 181 \\
\hline Luke B [75] & 2017 & USA & 2004-2010 & Cohort & 35.3 & 30.4 & IVF & 378 & 3538 & 493 & 6090 \\
\hline
\end{tabular}

$D O P$ date of publication, GDM gestational diabetes mellitus, ART assisted reproductive technology, Non-ART non-assisted reproductive technology, NA not available

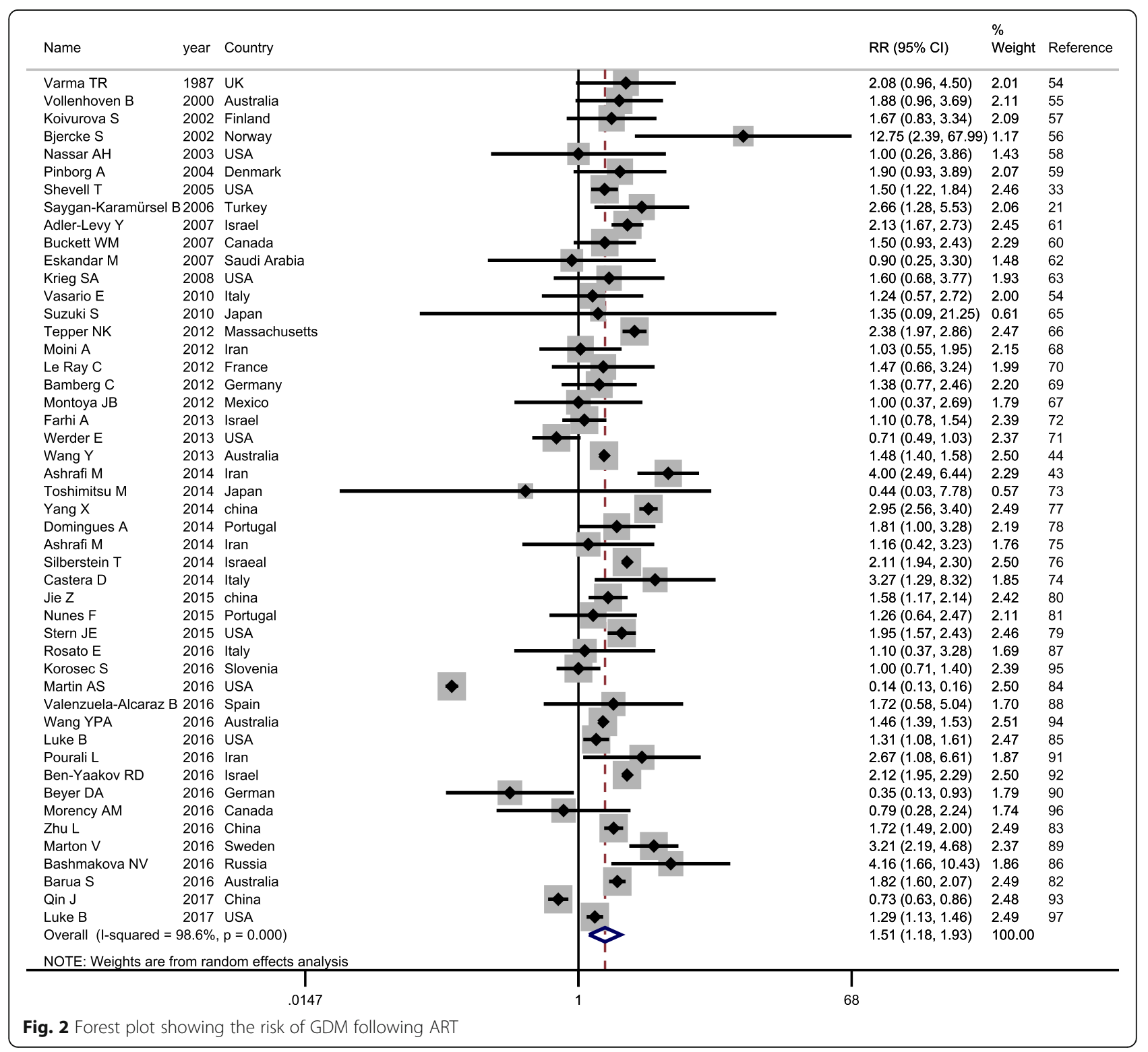


between studies, random effect models were also used. The relationship of ART and the risk of GDM was estimated using 48 included primary studies. The summary estimate of RR in this meta-analysis suggested that ART significantly was associated with higher risk of GDM (pooled $\mathrm{RR}=1.51,95 \% \mathrm{CI}=1.18-1.93, P=0.001$ ); that is, the risk of GDM in the ART group is 1.51 times compared to that in the non-ART group (Fig. 2 and Table 3).

\section{Heterogeneity analysis}

To check the heterogeneity between studies, chi-square test, I-squared, and Tau-squared were conducted. Chisquare analysis revealed that there was a significant heterogeneity between primary studies $\left(P<0.001, I^{2}=\right.$ 98.6\%); consequently, to pool the effect sizes in this study, a random effect model was used. To find the source of heterogeneity between studies, subgroup analyses were performed on the basis of study design, study region, and study period (Table 3). Even after the aforementioned subgroup analyses, heterogeneity across the studies did not diminish successfully in all subgroups; for that reason, some estimations of pooled RR were measured by the random effects model and only pooled RR for case control studies and the papers that were published between 1987 and 2010 were estimated by a mixed-effect model (Figs. 3, 4 and 5).

\section{Risk of publication bias}

Graphical (funnel plot) and statistical tools (Begg's and Egger's test) were done to test the existence of publication bias in the studies. The results of the symmetrical funnel plot (Fig. 6), Egger's test $(P=0.331)$, and Begg's test $(P=0.810)$ suggested that there was no significant publication bias in this study.

\section{Discussion}

The current study aimed to assess the impact of ART on GDM using a systematic review of related articles. This meta-analysis included 344,021 cases, in which 91,487 cases used ART to achieve pregnancy. Statistical approaches were determined based on the heterogeneity of the included studies and publication bias was checked. Several subgroups were defined based on the study design, time period, and region.

The results from this meta-analysis revealed that GDM is strongly affected by the use of ART. The relative risk of GDM was significant regarding the use of ART. Regarding the magnitude of the RR, the results from different study designs were in accordance. However, the included cross-sectional studies did not report a significant pooled RR in contrast to cohort and casecontrol studies and this might be due to the lower number of cross-sectional studies. Moreover, the impact of ART on GDM did not differ in two distinct periods of time (2010 as the cut-off point). In contrast to America, consistent results were found in two regions of Asia and Europe. The pooled RR resulting from American studies showed a higher risk of GDM among those in the nonART group.

The ART has been defined as treatments including in vitro handling of oocytes and sperm, and embryos, in which establishing pregnancy is the goal [76]. There have been many debates on the efficacy and safety of using ART regarding its increasing trend of use across most countries $[77,78]$. It has been shown that ART is responsible for a high number of adverse pregnancyrelated complications and obstetric outcomes such as polyhydramnios, low and very low infant birth weight, pregnancy-induced hypertension, pre-eclampsia, perinatal mortality, preterm and very preterm birth, placenta

Table 3 Summary of meta-analysis results and subgroups analysis

\begin{tabular}{|c|c|c|c|c|c|c|}
\hline \multirow[t]{2}{*}{ Groups } & \multirow{2}{*}{$\begin{array}{l}\text { \# of } \\
\text { studies }\end{array}$} & \multicolumn{3}{|c|}{ Test of association } & \multicolumn{2}{|c|}{ Heterogeneity } \\
\hline & & $\overline{R R}(95 \% \mathrm{Cl})$ & $P$ & Model & $\bar{P}$ & I square \\
\hline Total studies & 48 & $1.51(1.18-1.93)$ & 0.001 & Random & $<0.001$ & $98.9 \%$ \\
\hline \multicolumn{7}{|l|}{ Study design } \\
\hline Cohort & 41 & $1.44(1.07-1.95)$ & 0.021 & Random & $<0.001$ & $98.8 \%$ \\
\hline Case control & 4 & $2.04(1.65-2.51)$ & 0.001 & Fixed & 0.445 & 0 \\
\hline Cross-sectional & 3 & $1.99(0.93-4.26)$ & 0.095 & Random & $<0.001$ & $88.1 \%$ \\
\hline \multicolumn{7}{|l|}{ Time period } \\
\hline 1987-2010 & 14 & $1.75(1.50-2.05)$ & $<0.001$ & Fixed & 0.343 & $10.1 \%$ \\
\hline 2011-2017 & 34 & $1.42(1.05-1.90)$ & 0.022 & Random & $<0.001$ & $99.0 \%$ \\
\hline \multicolumn{7}{|l|}{ Region } \\
\hline Europe & 16 & $1.75(1.31-2.34)$ & $<0.001$ & Random & $<0.001$ & $65.3 \%$ \\
\hline Asia & 19 & $1.70(1.45-1.98)$ & $<0.001$ & Random & $<0.001$ & $94.2 \%$ \\
\hline America & 12 & $1.07(0.46-2.52)$ & $<0.001$ & Random & $<.001$ & $99.4 \%$ \\
\hline
\end{tabular}

$R R$ relative risk, $\mathrm{Cl}$ confidence interval 


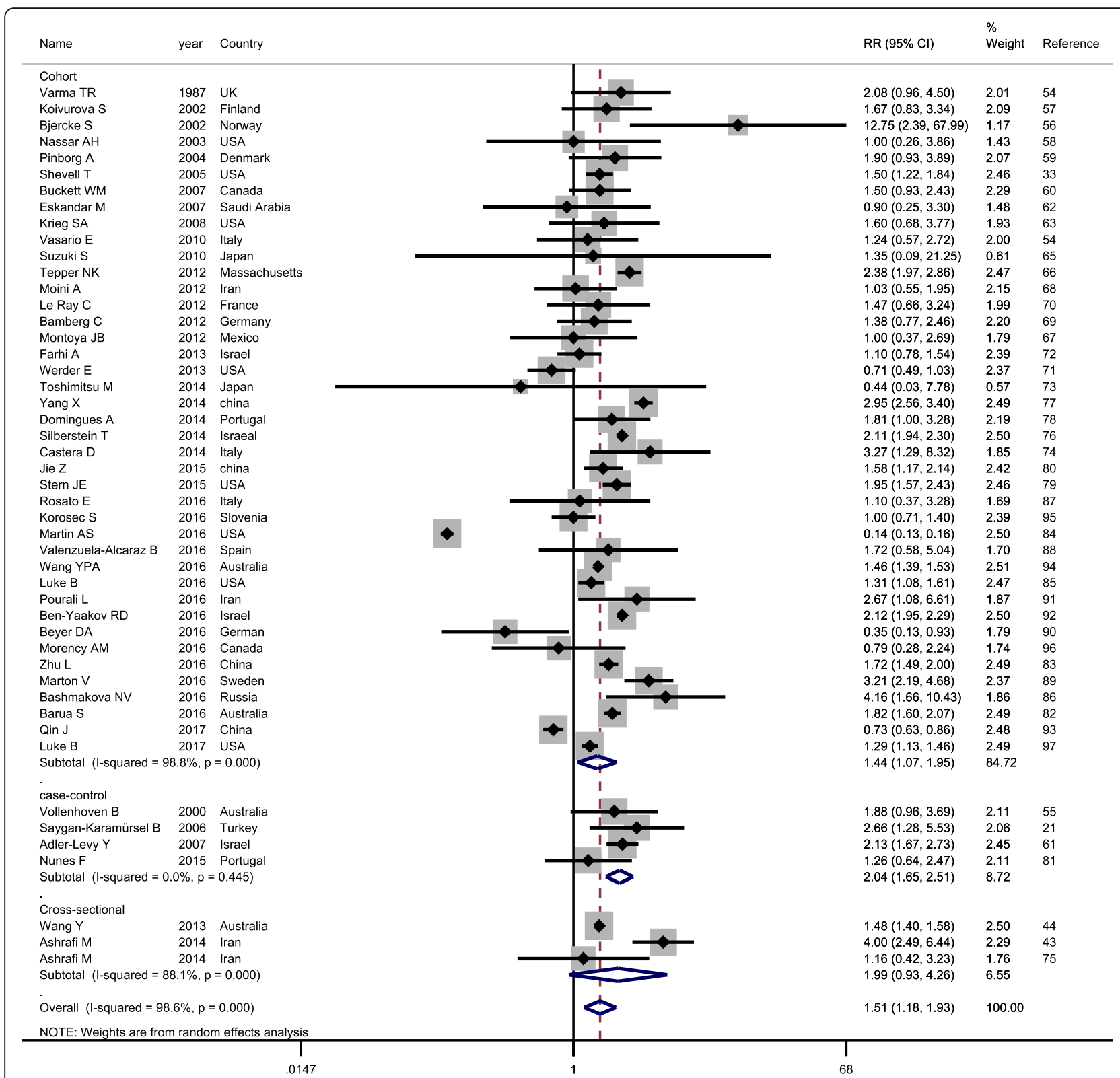

Fig. 3 Forest plot showing the risk of GDM following ART on the basis of study design

previa, antepartum hemorrhage, multiple pregnancy congenital malformation, higher risk of ectopic pregnancy, lower odds of vaginal delivery, postpartum hemorrhage, oligohydramnios, small for gestational age, and placental abruption [36, 79-83]. As mentioned, using ART was associated with GDM, which is diabetes diagnosed during pregnancy. Pregnancy may cause insulin resistance and hyperinsulinemia and can be followed by diabetes. GDM is defined as glucose intolerance with the first recognition during pregnancy and usually progresses in the second trimester [84]. GDM is associated with a large number of risk factors, such as elevated prepregnancy body mass index, older maternal age, history of GDM, diabetes among family members, polycystic ovary syndrome (PCOS), pre-existing hypertension, weight gain during pregnancy, smoking, ART, and higher parity [85-87]. The adverse effect of ART on GDM is discussed by several studies; however, the mechanism has not been well clarified $[48,52]$. Several hypotheses are introduced in which GDM is influenced by the use of ART, including the etiology of infertility, the drugs used in the treatment procedure, the hormonal levels, and metabolic and vascular factors [19, 52]. However, it has been revealed that maternal age is the most effective factor on GDM [88]. Wang et al. have discussed the association between GDM and ART through 


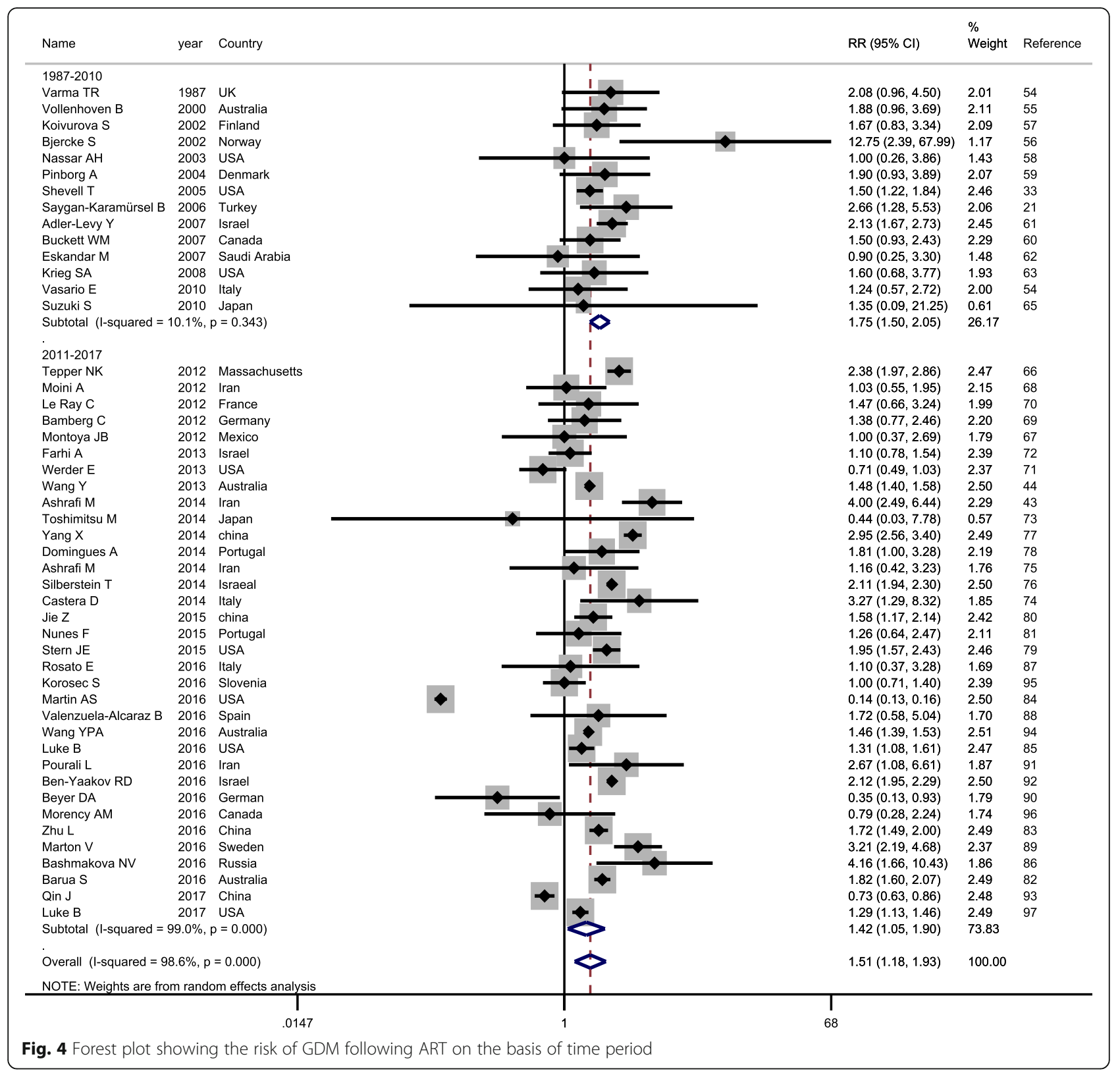

impaired glucose tolerance in comparison to those of spontaneous conceptions. Moreover, they have exposed that for singleton mothers, GDM was more common among cases that underwent ART. However, the risk increases for singleton mothers younger than 40 [48]. Double embryo transfer has been introduced as a significant factor for multiple gestational pregnancy, which is followed by an elevated risk of GDM [89, 90]. Vitthala et al. assessed the risk of monozygotic twins after ART using a systematic review and they revealed that in comparison to cleavage embryo transfer, GDM is more affected by blastocyst transfer [91]. Hammoud et al. addressed the scientific question of whether it is important to diagnose GDM by screening or symptoms. They showed that GDM is strongly related to large-forgestational-age births [92] and Sazonova et al. showed that babies after embryo transfer have a higher large for gestational age compared to fresh embryo transfer [93]. Pre-existing hypertension is associated with GDM [87] and this might be due to higher rates of ART mothers being of high maternal age [94]. Sibai and Ross assessed the pathophysiology and long-term consequences of hypertension in GDM. They demonstrated that mothers of twins are at a higher risk of GDM in contrast to those of singletons [90]. Risk of GDM among women with PCOS was assessed by Toulis et al. in a systematic review. They showed an increased likelihood of 


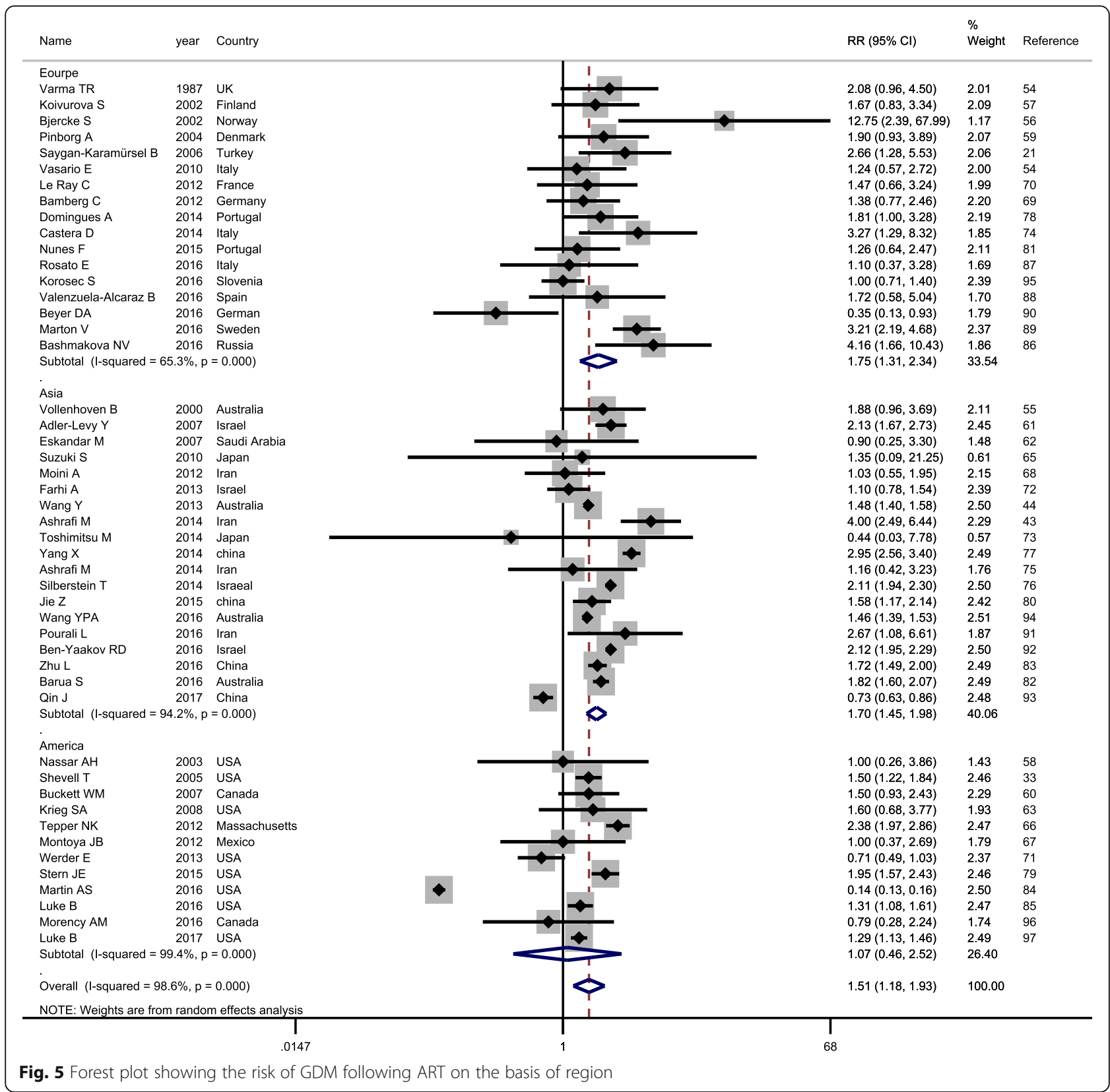

developing GDM among women with PCOS compared with general cases [95].

The current meta-analysis revealed a significant heterogeneity among the pooled studies, the cohort and cross-sectional studies, the studies conducted during 2011-2017, and the three regions of Asia, Europe, and America. Several statistical tools are available to check the heterogeneity of included studies in a meta-analysis and its selection mechanism depends on several factors such as sample size, the frequency of included studies, etc. The two common tests for heterogeneity (chi-square and the $I^{2}$ value) can result in controversial conclusions regarding the number of included studies and the magnitude of the relative risks [96]. There might be many reasons for the presence of heterogeneity in the results, such as different cultural and ethnic conditions and diversity in the amount of regions' development.

The present systematic review has several limitations that should be noted. First, the most important limitation for this study as for other meta-analysis studies is the lack of data for subgroup analysis based on type of pregnancy (singleton versus twin pregnancy), type of ART, or for data analysis controlling for known confounders. Second, there were no data on the relationship between ART and GDM for large regions such as Africa and Latin America, thus the generalizability of the 


\section{Funnel plot with pseudo $95 \%$ confidence limits}

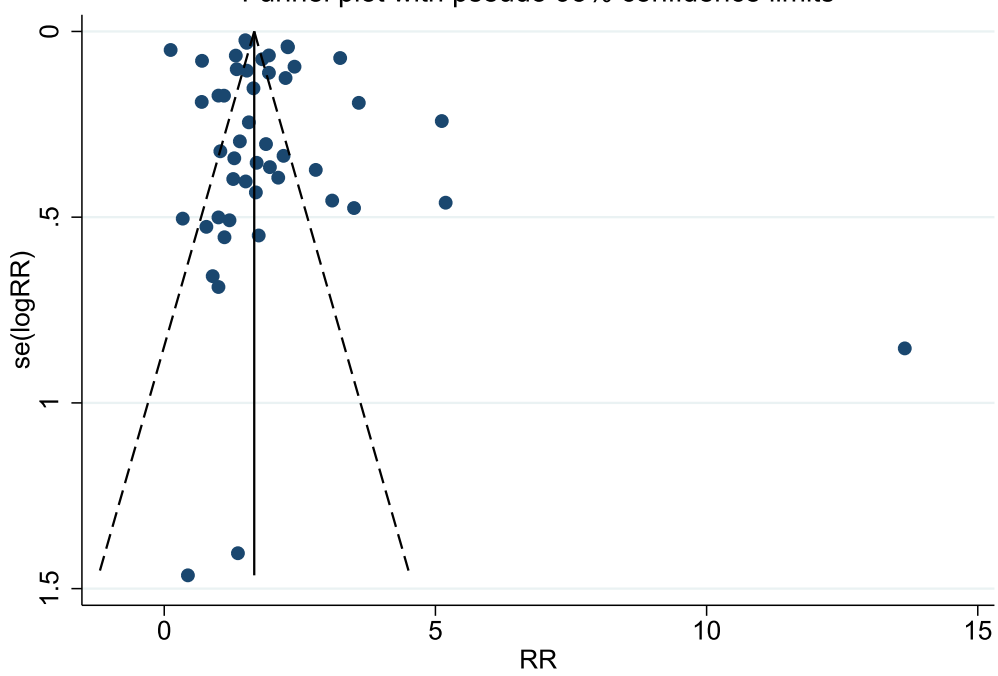

Fig. 6 Funnel plot to assess the presences of publication bias

results may be limited. Third, this study included only English papers.

In sum, the findings of the present systematic review and meta-analysis indicate that the use of ART is associated with a 1.51-fold increase in GDM. Women need to be counselled carefully before undergoing ART treatment about the possibility and risk of GDM.

\section{Abbreviations}

ART: Assisted reproductive technology; Cl: Confidence interval; GDM: Gestational diabetes mellitus; NOS: Newcastle-Ottawa Scale; PCOS: Polycystic ovary syndrome; RR: Relative risk

\section{Acknowledgments}

Not applicable.

\section{Authors' contributions}

AA, MM, ROS, SM, and AAH conceived the study. MM, PA, BN, SM, EKM and AA collected the data. AAH and SM analyzed the data. All authors contributed equally to draft the manuscript. All authors revised the manuscript and approved the final version.

\section{Funding}

Th is work received no specific grant from any agency in the public, commercial or not for profit sector.

\section{Availability of data and materials}

The datasets used and/or analyzed during the current study are available from the corresponding author on reasonable request.

\section{Ethics approval and consent to participate}

Not applicable.

\section{Consent for publication}

Not applicable.

\section{Competing interests}

The authors declare that they have no competing interests.

\section{Author details}

${ }^{1}$ Reproductive Epidemiology Research Center, Royan Institute for Reproductive Biomedicine, ACECR, Tehran, Iran. ${ }^{2}$ Department of Biostatistics, Faculty of Paramedical Sciences, Shahid Beheshti University of Medical
Sciences, Tehran, Iran. ${ }^{3}$ Department of Health Services Research, Institute of Psychology, Health, and Society, University of Liverpool, Liverpool, UK. ${ }^{4}$ School of Nursing and Midwifery, Guilan University of Medical Sciences, Rasht, Iran. ${ }^{5}$ Department of Epidemiology, School of Health, Arak University of Medical Sciences, Arak, Iran. ${ }^{6}$ Department of Biostatistics and Epidemiology, School of Public Health, Ahvaz Jundishapur University of Medical Sciences, Ahvaz, Iran. ${ }^{7}$ Department of Medical Ethics and Law, Reproductive Biomedicine Research Center, Royan Institute for Reproductive Biomedicine, ACECR, Tehran, Iran. ${ }^{8}$ Metabolic Diseases Research Center, Qazvin University of Medical Sciences, Qazvin, Iran.

Received: 5 July 2019 Accepted: 27 January 2020

Published online: 05 February 2020

\section{References}

1. Quintino-Moro A, Zantut-Wittmann DE, Tambascia M, Machado HdC, Fernandes A (2014) High prevalence of infertility among women with Graves' disease and Hashimoto's thyroiditis. Int J Endocrinol 2014:1-6

2. Kissin DM, Jamieson DJ, Barfield WD (2014) Monitoring health outcomes of assisted reproductive technology. N Engl J Med 371:91-93

3. De Mouzon J, Lancaster P, Nygren KG, Sullivan E, Zegers-Hochschild F, Mansour R, Ishihara O, Adamson D (2009) World collaborative report on assisted reproductive technology, 2002. Hum Reprod 24:2310-2320

4. Pandey S, Shetty A, Hamilton M, Bhattacharya S, Maheshwari A (2012) Obstetric and perinatal outcomes in singleton pregnancies resulting from IVF/ICSI: a systematic review and meta-analysis. Hum Reprod Update 18 485-503

5. Helmerhorst FM, Perquin DA, Donker D, Keirse MJ (2004) Perinatal outcome of singletons and twins after assisted conception: a systematic review of controlled studies. BMJ 328:261

6. Jackson RA, Gibson KA, Wu YW, Croughan MS (2004) Perinatal outcomes in singletons following in vitro fertilization: a meta-analysis. Obstet Gynecol 103:551-563

7. McDonald SD, Murphy K, Beyene J, Ohlsson A (2005) Perinatal outcomes of singleton pregnancies achieved by in vitro fertilization: a systematic review and meta-analysis. J Obstet Gynaecol Can 27:449-459

8. McGovern PG, Llorens AJ, Skurnick JH, Weiss G, Goldsmith LT (2004) Increased risk of preterm birth in singleton pregnancies resulting from in vitro fertilization-embryo transfer or gamete intrafallopian transfer: a meta-analysis. Fertil Steril 82:1514-1520

9. Salmeen K (2016) Gestational diabetes testing: making sense of the controversy. J Midwifery Womens Health 61:203-209

10. Bartolo S, Vambergue A, Deruelle P (2016) Screening for gestational diabetes: Still many unsolved issues. J Gynecol Obstet Biol Reprod (Paris) 45: 105-111 
11. Metzger BE, Coustan DR, Committee O (1998) Summary and recommendations of the fourth international workshop-conference on gestational diabetes mellitus. Diabetes Care 21:B161-B167

12. Association, A.D (2004) Gestational diabetes mellitus. Diabetes Care 27:S88-S90

13. Cheng YW, Block-Kurbisch I, Caughey AB (2009) Carpenter-Coustan criteria compared with the national diabetes data group thresholds for gestational diabetes mellitus. Obstet Gynecol 114:326-332

14. Kuhl C (1998) Etiology and pathogenesis of gestational diabetes. Diabetes Care 21:B19-B26

15. Schmidt MI, Duncan BB, Reichelt AJ, Branchtein L, Matos MC, e Forti AC, Spichler ER, Pousada JM, Teixeira MM, Yamashita T (2001) Gestational diabetes mellitus diagnosed with a 2-h 75-g oral glucose tolerance test and adverse pregnancy outcomes. Diabet Care 24:1151-1155

16. Casey BM, Lucas MJ, McIntire DD, Leveno KJ (1997) Pregnancy outcomes in women with gestational diabetes compared with the general obstetric population. Obstet Gynecol 90:869-873

17. Bellamy L, Casas J-P, Hingorani AD, Williams D (2009) Type 2 diabetes mellitus after gestational diabetes: a systematic review and meta-analysis. Lancet 373:1773-1779

18. Cunningham F, Leveno K, Bloom S, Spong CY, Dashe J (2014) Williams obstetrics. Mcgraw-hill, New York

19. Grady R, Alavi N, Vale R, Khandwala M, McDonald SD (2012) Elective single embryo transfer and perinatal outcomes: a systematic review and metaanalysis. Fertil Steril 97:324-331

20. Zaib-un-Nisa S, Ghazal-Aswad S, Badrinath P (2003) Outcome of twin pregnancies after assisted reproductive techniques-a comparative study. Eur J Obstet Gynecol Reprod Biol 109:51-54

21. Saygan-Karamürsel B, Tekşam Ö, Aksu T, Yurdakök M, Önderoğlu L (2006) Perinatal outcomes of spontaneous twins compared with twins conceived through intracytoplasmic sperm injection. J Perinat Med 34:132-138

22. Adler-Levy Y, Lunenfeld E, Levy A (2007) Obstetric outcome of twin pregnancies conceived by in vitro fertilization and ovulation induction compared with those conceived spontaneously. Eur J Obstet Gynecol Reprod Biol 133:173-178

23. Kennelly M, McAuliffe F (2016) Prediction and prevention of Gestational Diabetes: an update of recent literature. Eur J Obstet Gynecol Reprod Biol 202:92-98

24. Marchand E, Poncelet C, Carbillon L, Pharisien I, Tigaizin A, Chanelles O (2011) Is there more complications with pregnancies from the assisted reproductive technology than spontaneous pregnancies? A retrospective study over 6 years. J Gynecol Obstet Biol Reprod (Paris) 40:522-528

25. Moher D, Liberati A, Tetzlaff J, Altman DG (2009) Preferred reporting items for systematic reviews and meta-analyses: the PRISMA statement. Ann Intern Med 151:264-269

26. Wells GA, Shea B, O'connell D, Peterson J, Welch V, Losos M, Tugwell P. The Newcastle-Ottawa Scale (NOS) for assessing the quality of nonrandomised studies in meta-analyses. Available at: http://www.ohri.ca/programs/clinical_ epidemiology/oxford.asp. Accessed 30 July 2017.

27. Higgins J, Thompson SG (2002) Quantifying heterogeneity in a metaanalysis. Stat Med 21:1539-1558

28. Begg CB, Mazumdar M (1994) Operating characteristics of a rank correlation test for publication bias. Biometrics 50:1088-1101

29. Egger M, Smith GD, Schneider M, Minder C (1997) Bias in meta-analysis detected by a simple, graphical test. BMJ 315:629-634

30. Varma TR, Patel RH (1987) Outcome of pregnancy following investigation and treatment of infertility. Int J Gynaecol Obstet 25:113-120

31. Vollenhoven B, Clark S, Kovacs G, Burger H, Healy D (2000) Prevalence of gestational diabetes mellitus in polycystic ovarian syndrome (PCOS) patients pregnant after ovulation induction with gonadotrophins. Aust N Z J Obstet Gynaecol 40:54-58

32. Bjercke S, Dale PO, Tanbo T, Storeng R, Ertzeid G, Åbyholm T (2002) Impact of insulin resistance on pregnancy complications and outcome in women with polycystic ovary syndrome. Gynecol Obstet Invest 54:94-98

33. Koivurova S, Hartikainen AL, Karinen L, Gissler M, Hemminki E, Martikainen $H$, Tuomivaara L, Järvelin MR (2002) The course of pregnancy and delivery and the use of maternal healthcare services after standard IVF in Northern Finland 1990-1995. Hum Reprod 17:2897-2903

34. Nassar AH, Usta IM, Rechdan JB, Harb TS, Adra AM, Abu-Musa AA (2003) Pregnancy outcome in spontaneous twins versus twins who were conceived through in vitro fertilization. Am J Obstet Gynecol 189:513-518

35. Pinborg A, Loft A, Schmidt L, Langhoff-Roos J, Andersen AN (2004) Maternal risks and perinatal outcome in a Danish national cohort of 1005 twin pregnancies: the role of in vitro fertilization. Acta Obstet Gynecol Scand 83:75-84
36. Shevell T, Malone FD, Vidaver J, Porter TF, Luthy DA, Comstock CH, Hankins GD, Eddleman K, Dolan S, Dugoff L (2005) Assisted reproductive technology and pregnancy outcome. Obstet Gynecol 106:1039-1045

37. Buckett WM, Chian RC, Holzer H, Dean N, Usher R, Tan SL (2007) Obstetric outcomes and congenital abnormalities after in vitro maturation, in vitro fertilization, and intracytoplasmic sperm injection. Obstet Gynecol 110:885-891

38. Eskandar M (2007) Outcome of twin ICSI pregnancy compared with spontaneous conceived twin pregnancy: A prospective, controlled, observational study. Middle East Fertil Soc J 12:97-101

39. Krieg SA, Henne MB, Westphal LM (2008) Obstetric outcomes in donor oocyte pregnancies compared with advanced maternal age in in vitro fertilization pregnancies. Fertil Steril 90:65-70

40. Vasario E, Borgarello V, Bossotti C, Libanori E, Biolcati M, Arduino S, Spinell R, Piane LD, Revelli A, Todros T (2010) IVF twins have similar obstetric and neonatal outcome as spontaneously conceived twins: A prospective followup study. Reprod BioMed Online 21:422-428

41. Suzuki S, Miyake H (2010) Perinatal outcomes of elderly primiparous dichorionic twin pregnancies conceived by in vitro fertilization compared with those conceived spontaneously. Arch Gynecol Obstet. 281:87-90

42. Tepper NK, Farr SL, Cohen BB, Nannini A, Zhang Z, Anderson JE, Jamieson DJ, Macaluso M (2012) Singleton preterm birth: risk factors and association with assisted reproductive technology. Matern Child Health J 16:807-813

43. Montoya JB, Muñoz ER, Rivera EC, Villaseñor BL, De La Jara Díaz JF, Canedo TH (2012) Resultados perinatales adversos en mujeres mexicanas con embarazos gemelares por reproducción asistida vs gemelares espontáneos. Ginecol Obstet Mex 80:445-453

44. Moini A, Shiva M, Arabipoor A, Hosseini R, Chehrazi M, Sadeghi M (2012) Obstetric and neonatal outcomes of twin pregnancies conceived by assisted reproductive technology compared with twin pregnancies conceived spontaneously: a prospective follow-up study. Eur J Obstet Gynecol Reprod Biol 165:29-32

45. Bamberg C, Fotopoulou C, Neissner P, Slowinski T, Dudenhausen JW, Proquitte H, Bührer C, Henrich W (2012) Maternal characteristics and twin gestation outcomes over 10 years: impact of conception methods. Fertil Steril 98:95-101

46. Le Ray C, Scherier S, Anselem O, Marszalek A, Tsatsaris V, Cabrol D, Goffinet F (2012) Association between oocyte donation and maternal and perinatal outcomes in women aged 43 years or older. Hum Reprod 27:896-901

47. Werder E, Mendola P, Männistö T, O'Loughlin J, Laughon SK (2013) Effect of maternal chronic disease on obstetric complications in twin pregnancies in a United States cohort. Fertil Steril 100:142-149

48. Wang Y, Nikravan R, Smith H, Sullivan E (2013) Higher prevalence of gestational diabetes mellitus following assisted reproductive technology treatment. Hum Reprod 28:2554-2561

49. Farhi A, Reichman B, Boyko V, Hourvitz A, Ron-El R, Lerner-Geva L (2013) Maternal and neonatal health outcomes following assisted reproduction. Reprod. BioMed. Online 26:454-461

50. Toshimitsu M, Nagamatsu T, Nagasaka T, Iwasawa-Kawai Y, Komatsu A, Yamashita T, Osuga Y, Fujii T (2014) Increased risk of pregnancy-induced hypertension and operative delivery after conception induced by in vitro fertilization/intracytoplasmic sperm injection in women aged 40 years and older. Fertil Steril 102:1065-1070

51. Caserta D, Bordi G, Stegagno M, Filippini F, Podagrosi M, Roselli D, Moscarini M (2014) Maternal and perinatal outcomes in spontaneous versus assisted conception twin pregnancies. Eur J Obstet Gynecol Reprod Biol 174:64-69

52. Ashrafi M, Gosili R, Hosseini R, Arabipoor A, Ahmadi J, Chehrazi M (2014) Risk of gestational diabetes mellitus in patients undergoing assisted reproductive techniques. Eur J Obstet Gynecol Reprod Biol 176:149-152

53. Ashrafi M, Sheikhan F, Arabipoor A, Hosseini R, Nourbakhsh F, Zolfaghari Z (2014) Gestational diabetes mellitus risk factors in women with polycystic ovary syndrome (PCOS). Eur J Obstet Gynecol Reprod Biol 181:195-199

54. Silberstein T, Levy A, Harlev A, Saphier O, Sheiner E (2014) Perinatal outcome of pregnancies following in vitro fertilization and ovulation induction. J Matern Fetal Neonatal Med 27:1316-1319

55. Yang X, Li Y, Li C, Zhang W (2014) Current overview of pregnancy complications and live-birth outcome of assisted reproductive technology in mainland China. Fertil Steril 101:385-391

56. Domingues AP, Dinis SR, Belo A, Couto D, Fonseca E, Moura P (2014) Impact of induced pregnancies in the obstetrical outcome of twin pregnancies. Fertil Steril 101:172-177

57. Stern JE, Luke B, Tobias M, Gopal D, Hornstein MD, Diop H (2015) Adverse pregnancy and birth outcomes associated with underlying diagnosis with 
and without assisted reproductive technology treatment. Fertil Steril 103: $1438-1445$

58. Jie Z, Yiling D, Ling Y (2015) Association of assisted reproductive technology with adverse pregnancy outcomes. Iran J Reprod Med 13:169-180

59. Nunes F, Noronha N, Neves F, Taborda A, Silva IS, Almeida M (2015) Obstetric And Perinatal Outcomes In Multifetal Gestations: Assisted Reproductive Technology Versus Spontaneous Conception. J Perinat Med 43:1208

60. Barua S, Hng TM, Smith H, Bradford J, McLean M (2017) Ovulatory disorders are an independent risk factor for pregnancy complications in women receiving assisted reproduction treatments. Aust N Z J Obstet Gynaecol 57: 286-293

61. Zhu LL, Zhang Y, Liu YF, Zhang RJ, Wu YQ, Huang Y, Liu F, Li MG, Sun SJ, Xing LF et al (2016) Maternal and Live-birth Outcomes of Pregnancies following Assisted Reproductive Technology: A Retrospective Cohort Study. Sci Rep:6

62. Martin AS, Monsour M, Kissin DM, Jamieson DJ, Callaghan WM, Boulet SL (2016) Trends in severe maternal morbidity after assisted reproductive technology in the United States, 2008-2012. Obstet Gynecol 127:59-66

63. Luke B, Stern JE, Kotelchuck M, Declercq ER, Anderka M, Diop H (2016) Birth outcomes by infertility treatment: Analyses of the population-based cohort: Massachusetts outcomes study of assisted reproductive technologies (MOSART). J Reprod Med 61:114-127

64. Bashmakova NV, Davydenko NB, Malgina GB, Putilova NV (2016) Epidemiology of critical states during pregnancy after assisted reproductive technologies. Gynecol Endocrinol 32:47-51

65. Rosato E, Perrone G, Capri O, Galoppi P, Candelieri M, Marcoccia E, Schiavi MC, Zannini I, Brunelli R (2016) Hypertension and early menopause after the use of assisted reproductive technologies in women aged 43 years or older: Long-term follow-up study. J Obstet Gynaecol Res 42:1782-1788

66. Valenzuela-Alcaraz B, Crispi F, Manau D, Cruz-Lemini M, Borras A, Balasch J, Gratacos E (2016) Differential effect of mode of conception and infertility treatment on fetal growth and prematurity. J Matern Fetal Neonatal Med 29:3879-3884

67. Marton V, Zadori J, Kozinszky Z, Kereszturi A (2016) Prevalences and pregnancy outcome of vanishing twin pregnancies achieved by in vitro fertilization versus natural conception. Fertil Steril 106:1399-1406

68. Beyer DA, Amari F (2016) Maternal risk factors and neonatal outcomes after ART treatment - A German monocenter experience. Middle East Fertil Soc J 21:155-160

69. Pourali L, Ayati S, Jelodar S, Zarifian A, Andalibi MSS (2016) Obstetrics and perinatal outcomes of dichorionic twin pregnancy following art compared with spontaneous pregnancy. Int J Reprod Biomed (Yazd) 14:317-322

70. Ben-Yaakov RD, Kessous R, Shoham-Vardi I, Sergienko R, Pariente G, Sheiner E (2016) Fertility treatments in women who become pregnant and carried to viability, and the risk for long-term maternal cardiovascular morbidity. Am J Perinatol 33:1388-1393

71. Qin J, Liu X, Sheng X, Wang H, Gao S (2016) Assisted reproductive technology and the risk of pregnancy-related complications and adverse pregnancy outcomes in singleton pregnancies: A meta-analysis of cohort studies. Fertil Steril 105:73-85e76

72. Wang YPA, Chughtai AA, Farquhar CM, Pollock W, Lui K, Sullivan EA (2016) Increased incidence of gestational hypertension and preeclampsia after assisted reproductive technology treatment. Fertil Steril 105:920-926

73. Korosec S, Frangez HB, Steblovnik L, Verdenik I, Bokal EV (2016) Independent factors influencing large-for-gestation birth weight in singletons born after in vitro fertilization. J Assist Reprod Genet 33:9-17

74. Morency AM, Shah PS, Seaward PG, Whittle W, Murphy KE (2016) Obstetrical and neonatal outcomes of triplet births - spontaneous versus assisted reproductive technology conception. J Matern Fetal Neonatal Med 29:938-943

75. Luke B, Gopal D, Cabral H, Stern JE, Diop H (2017) Adverse pregnancy, birth, and infant outcomes in twins: effects of maternal fertility status and infant gender combinations; the Massachusetts Outcomes Study of Assisted Reproductive Technology. Am J Obstet Gynecol 217:330.e331-330.e315

76. Zegers-Hochschild F, Adamson GD, de Mouzon J, Ishihara O, Mansour R, Nygren K, Sullivan E, Van der Poel S (2009) The international committee for monitoring assisted reproductive technology (ICMART) and the world health organization (WHO) revised glossary on ART terminology, 2009. Hum Reprod 24:2683-2687

77. Adamson GD, de Mouzon J, Lancaster P, Nygren K-G, Sullivan E, ZegersHochschild F, Technology, I.C.f.M.A.R (2006) World collaborative report on in vitro fertilization, 2000. Fertil Steril 85:1586-1622
78. Dickey RP (2007) The relative contribution of assisted reproductive technologies and ovulation induction to multiple births in the United States 5 years after the Society for Assisted Reproductive Technology/American Society for Reproductive Medicine recommendation to limit the number of embryos transferred. Fertil Steril 88:1554-1561

79. Stephansson O, Kieler H, Granath F, Falconer H (2009) Endometriosis, assisted reproduction technology, and risk of adverse pregnancy outcome. Hum Reprod 24:2341-2347

80. Qin J, Liu X, Sheng X, Wang H, Gao S (2016) Assisted reproductive technology and the risk of pregnancy-related complications and adverse pregnancy outcomes in singleton pregnancies: a meta-analysis of cohort studies. Fertil Steril 105:73-85

81. Qin J, Wang H, Sheng X, Liang D, Tan H, Xia J (2015) Pregnancy-related complications and adverse pregnancy outcomes in multiple pregnancies resulting from assisted reproductive technology: a meta-analysis of cohort studies. Fertil Steril 103:1492-1508

82. Kouhkan A, Khamseh ME, Pirjani R, Moini A, Arabipoor A, Maroufizadeh S, Hosseini R, Baradaran HR (2018) Obstetric and perinatal outcomes of singleton pregnancies conceived via assisted reproductive technology complicated by gestational diabetes mellitus: a prospective cohort study. BMC Pregnancy Childbirth 18:495

83. Almasi-Hashiani A, Omani-Samani R, Mohammadi M, Amini P, Navid B, Alizadeh A, Morasae EK, Maroufizadeh S (2019) Assisted reproductive technology and the risk of preeclampsia: an updated systematic review and meta-analysis. BMC Pregnancy Childbirth 19:149

84. Association, A.D (2014) Diagnosis and classification of diabetes mellitus. Diabetes Care 37:S81-\$90

85. DeSisto CL, Kim SY, Sharma AJ (2014) Prevalence estimates of gestational diabetes mellitus in the United States, pregnancy risk assessment monitoring system (PRAMS), 2007-2010. Prev Chronic Dis 11:E104

86. Leng J, Shao P, Zhang C, Tian H, Zhang F, Zhang S, Dong L, Li L, Yu Z, Chan JC (2015) Prevalence of gestational diabetes mellitus and its risk factors in Chinese pregnant women: a prospective population-based study in Tianjin, China. Plos one 10:e0121029

87. Kjerulff LE, Sanchez-Ramos L, Duffy D (2011) Pregnancy outcomes in women with polycystic ovary syndrome: a metaanalysis. Am J Obstet Gynecol 204(558):e551-e556

88. Bener A, Saleh NM, Al-Hamaq A (2011) Prevalence of gestational diabetes and associated maternal and neonatal complications in a fast-developing community: global comparisons. Int J Womens Health 3:367-373

89. Pinborg A, Lidegaard $\varnothing$, la Cour Freiesleben N, Andersen AN (2007) Vanishing twins: a predictor of small-for-gestational age in IVF singletons. Hum Reprod 22:2707-2714

90. Sibai BM, Ross MG (2010) Hypertension in gestational diabetes mellitus: pathophysiology and long-term consequences. J Matern Fetal Neonatal Med 23:229-233

91. Vitthala S, Gelbaya T, Brison D, Fitzgerald C, Nardo L (2008) The risk of monozygotic twins after assisted reproductive technology: a systematic review and meta-analysis. Hum Reprod Update 15:45-55

92. Hammoud NM, de Valk HW, Biesma DH, Visser GH (2013) Gestational diabetes mellitus diagnosed by screening or symptoms: does it matter? J Matern Fetal Neonatal Med 26:103-105

93. Sazonova A, Källen K, Thurin-Kjellberg A, Wennerholm U-B, Bergh C (2012) Obstetric outcome in singletons after in vitro fertilization with cryopreserved/thawed embryos. Hum Reprod 27:1343-1350

94. Luke B, Brown MB (2007) Elevated risks of pregnancy complications and adverse outcomes with increasing maternal age. Hum Reprod 22:1264-1272

95. Toulis KA, Goulis DG, Kolibianakis EM, Venetis CA, Tarlatzis BC, Papadimas I (2009) Risk of gestational diabetes mellitus in women with polycystic ovary syndrome: a systematic review and a meta-analysis. Fertil Steril 92:667-677

96. Higgins, J.P. and Green, S. (2011) Cochrane Handbook for Systematic Reviews of Interventions Version 5.1.0. The Cochrane Collaboration, 2011. Available from www.cochrane-handbook.org.

\section{Publisher's Note}

Springer Nature remains neutral with regard to jurisdictional claims in published maps and institutional affiliations. 